\title{
A Novel Method for the Analysis of Slash Cuts to Clothing
}

\section{Esta Bostock, Gareth Michael Burdon Parkes and Graham Williams*}

Forensic Biology Group, School of Applied Sciences, University of Huddersfield, UK

\begin{abstract}
Slash attacks form a major element of physical assaults, involving a sharp implement such as a knife. If a slash attack is inflicted onto a surface covered with fabric, such as clothing, then that fabric may receive a slash cut.

Investigation of the slash cut can provide further information regarding the nature of the implement and the action of the attack.

This study aims to identify a quantifiable correlation between the nature of the slash cut and the implement causing it. The study also aims to develop a method of categorising the damage, as well as a way of measuring the sharpness of a knife without blunting the blade.

Two new simple techniques were developed and applied to a range of household implements. A quantifiable correlation could be seen between the damage categorisation and the relative sharpness of the implement. The degree of this correlation varied depending on the fabric type.
\end{abstract}

Keywords: Forensic science; Clothing damage; Slash; Cuts

\section{Introduction}

Knife crimes include possession of an offensive weapon, physical assaults such as grievous bodily harm and homicides. Both Ciallella et al. [1] and Daeid et al. [2] agree that sharp force violence is one of the most common ways of committing a homicide or physical assault.

Body injuries normally carry more information and are more suitable for comparative analysis and identification of the implement than clothing damage characteristics. However, in separate cases, the investigation of clothing damage can provide information about the implement that cannot be gained from the investigation of wounds [3]. Such cases include those where wound examination may not be available, such as when the deceased is in an advanced state of decomposition or where the recipient of the injury has survived following medical intervention.

Two studies by Bleetman et al. $[4,5]$ indicate that slash wounds are more common than stab type wounds on the scalp, face, neck, limbs and buttocks, and therefore many injuries caused by edged weapons seen in clinical practice are from slashing attacks rather than from stabbings. Bleetman et al. $[4,5]$ add that approximately one third of assault victims attending hospital have been injured by an assailant using a knife. Most of the patients presented with superficial slash type wounds [5].

A slash cut is generally produced by a sharp-edged tool (such as a knife, a razor blade or a scalpel) travelling in an arc via a swinging motion. The slash may not penetrate the material completely or may penetrate intermittently, which means that the cuts were not continuous. Unlike most stab cuts, which have a short nick at the end of the damage, a slash cut starts and finishes with a smooth $\mathrm{V}$ shape $[6,7]$.

Horsfall et al. [8] states that there are four different actions that can occur when a knife penetrates fabric (Table 1).

In general, the blunter the point of the knife, the more difficult it is to make the initial penetration of the fabric; therefore there would be more distortion around the penetration point. The sharpness of the blade will affect the shape of the severance. A sharper blade will neatly cut yarn as it travels through fabric, with little or no fabric distortion [8], whereas a blunter knife will not cut through yarn as neatly.

Taupin et al. [9] state that by examining the characteristics of the fabric damage, it may be possible to indicate the type of implement used.

However, the current technique involves placing the damaged garment over a polystyrene block, prior to a test cut being applied using the suspected implement. A visual comparison is then carried out on both the suspect cut and the test cut, in order to determine whether the suspected implement could have caused the resulting damage. This methodology lacks transparency and it is very difficult to challenge, as it is based upon a scientist's highly subjective opinion.

Given the current requirements, especially in the United Kingdom, of increasing transparency and quality assurance of evidence, it has been recognised that this niche discipline needs to be more robust; therefore, alternative or complementary methodologies need to be explored.

The aim of this study was to investigate the effect of the sharpness

\begin{tabular}{|l|l|}
\hline Pushing & Moves yarns out of the plane of the fabric \\
\hline Cutting & Due to sharp transverse pressure on the fibres \\
\hline Shearing & Due to blunt transverse pressure on the fibres \\
\hline Tearing & Cause by the fibres being extended to break \\
\hline
\end{tabular}

Table 1: Definitions of different actions as defined by Horsfall et al. [8].

*Corresponding author: Graham Williams, Forensic Biology Group, School of Applied Sciences, University of Huddersfield, Huddersfield, West Yorkshire, UK, E-mail: graham.williams@hud.ac.uk

Received August 22, 2013; Accepted September 18, 2013; Published September 23, 2013

Citation: Bostock E, Burdon Parkes GM, Williams G (2013) A Novel Method for the Analysis of Slash Cuts to Clothing. J Forensic Res 4: 197. doi:10.4172/21577145.1000197

Copyright: @ 2013 Bostock E, et al. This is an open-access article distributed under the terms of the Creative Commons Attribution License, which permits unrestricted use, distribution, and reproduction in any medium, provided the original author and source are credited. 
Citation: Bostock E, Burdon Parkes GM, Williams G (2013) A Novel Method for the Analysis of Slash Cuts to Clothing. J Forensic Res 4: 197. doi:10.4172/2157-7145.1000197

Page 2 of 7

of the slashing implement; for which a new technique was developed to measure the blade sharpness. This is referred to as the 'relative sharpness index' or RSI. A method of quantifying the extent of the damage was also devised, which is referred to as damage categorisation.

\section{Methods and Materials}

\section{Measuring blade sharpness}

The implement was placed in a clamp with the blade facing up. A $20 \mathrm{~cm}$ loop of thread was then placed on the blade, $1 \mathrm{~cm}$ away from the tip of the implement. Weights were then added to the other end of the thread in increments. The weight required to cut the thread was then recorded. This method utilises the principle that the sharper the blade, the less force is required to cut the fabric. The use of the thread means that only a very small section of the blade is used, therefore the sharpness of the blade is only slightly compromised by repeated testing. For this study, the blade sharpness was measured using a range of different threads, these consisted of firstly, $100 \%$ cotton sewing thread and $100 \%$ polyester thread, with both of these having a tight organised yarn. Also used was $100 \%$ cotton sheeting thread and $100 \%$ silk thread, which both had a loose and unorganised yarn. The overall performance of each separate thread was compared.

This method of measuring blade sharpness was developed so that it did not cause the blade to become more blunt over time, thus allowing for effective quality control and review by other forensic practitioners, as well as reducing drift in the data collected as the blade became blunter.

Sharpness can be subjective, for example one implement can be sharper than another, but still be considered by some as being blunt if there is nothing with which to compare it. Therefore, for the purpose of this study, a relative sharpness index (RSI) was developed, which allows for variables in measurements between groups. This was done by determining the ratio of sharpness of nineteen blades (Table 2) to an implement considered to be 'ultimately' blunt. To represent the implement of ultimate bluntness, a round smooth wooden dowel was used. The weight required to break a thread around the dowel was determined (which also corresponded to the maximum tensile strength of the thread) and the mean was used as the denominator of the ratio. This ratio was applied to each individual measurement and it is this ratio which forms the basis of the statistical analyses. This test was applied to each thread type separately.

\section{Categorising clothing damage}

A difficulty associated with assessing damage to clothing is how to quantify the extent of the damage. It was decided that an effective way of doing this was by categorisation, which helped to minimise the subjective nature of the fabric damage analysis. Categorisation of forensic evidence is already in use, for example categorising the quantity of spermatozoa on a slide [10], which is frequently used in a court of law.

Johnson [11] states that most textile items are compound structures composed of up to four levels, these consist of fibres which are formed into yarns (or threads), the yarns are then interlaced into fabrics either by weaving, knitting etc and the fourth level is the final article i.e. clothing etc. In order to categorise the clothing damage, three levels of observation were employed; fabric level, yarn level and fibre level.

At each level, a score was given. Table 2 gives an indication of the categorisation and associated scoring. The observations and categorisations were then reviewed and agreed by a second person. The scores at each level were then added together to give a range of $0-8$, with 0 representing the smoothest damage and 8 representing the roughest, or most ragged, damage. This combined score was then used as raw data for the statistical analyses.

Both fabric level and yarn level were taken at x16 magnification, whilst fibre level was taken using $\mathrm{x} 40$ magnification.

i. Fabric level, this would be categorised as 0, due to the neatness of the cut (Figure 1).

ii. Fabric level, this would be categorised as 1, due to the slight unevenness of the cut (Figure 2).

iii. Yarn level, this would be categorised as 0, due to the cut having no loose yarns (Figure 3).

iv. Yarn level, this would be categorised as 3, due to the cut having two or more loose yarns (Figure 4).

v. Fibre level, this would be categorised as 0 , due to the cut having no loose fibres (Figure 5).

vi. Fibre level, this would be categorised as 2, due to the cut having a majority of loose fibres. However if the bottom yarns also had

\begin{tabular}{|l|l|l|l|}
\hline Score & Fabric level & Yarn level & Fibre level \\
\hline 0 & Smooth cut & No loose yarn & No loose fibres \\
\hline 1 & Slightly uneven & One loose yarn & Few loose fibres \\
\hline 2 & Very uneven & Two loose yarns & Majority loose fibres \\
\hline 3 & & >Two loose yarns & All loose fibres \\
\hline
\end{tabular}

Table 2: The basis for categorising damage to clothing is shown in this table.

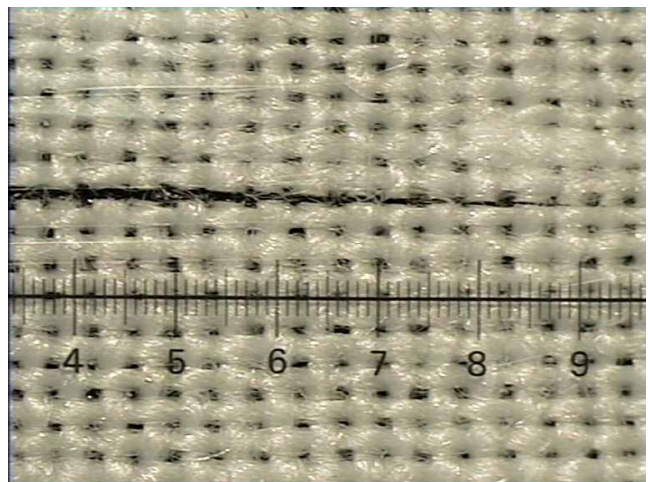

Figure 1: Fabric level, this would be categorised as 0 , due to the neatness of the cut.

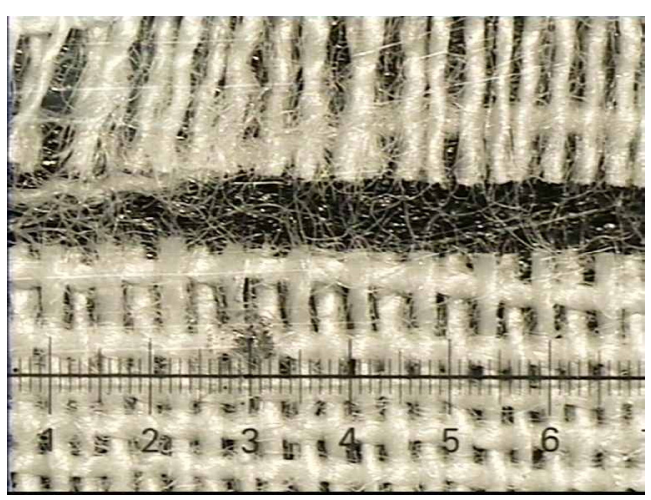

Figure 2: Fabric level, this would be categorised as 1, due to the slight unevenness of the cut. 
Citation: Bostock E, Burdon Parkes GM, Williams G (2013) A Novel Method for the Analysis of Slash Cuts to Clothing. J Forensic Res 4: 197. doi:10.4172/2157-7145.1000197

Page 3 of 7

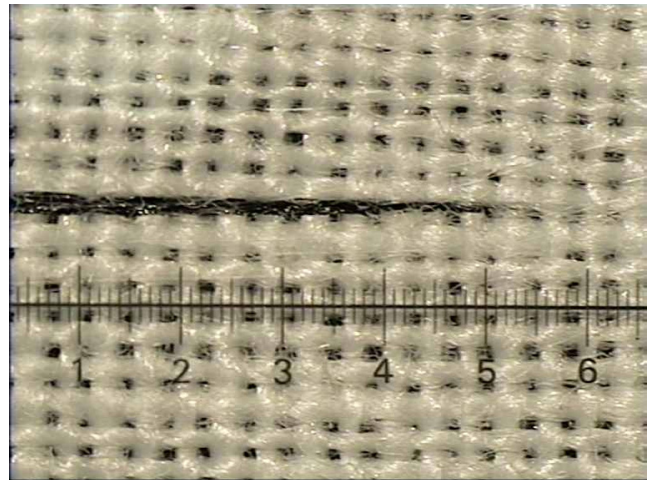

Figure 3: Yarn level, this would be categorised as 0 , due to the cut having no loose yarns.

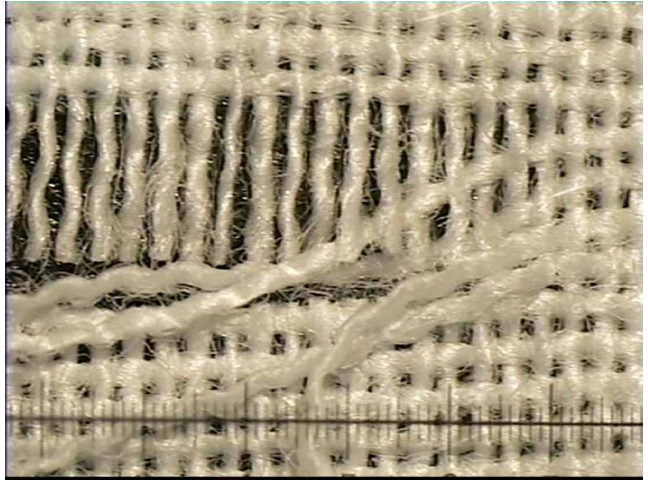

Figure 4: Yarn level, this would be categorised as 3, due to the cut having two or more loose yarns.

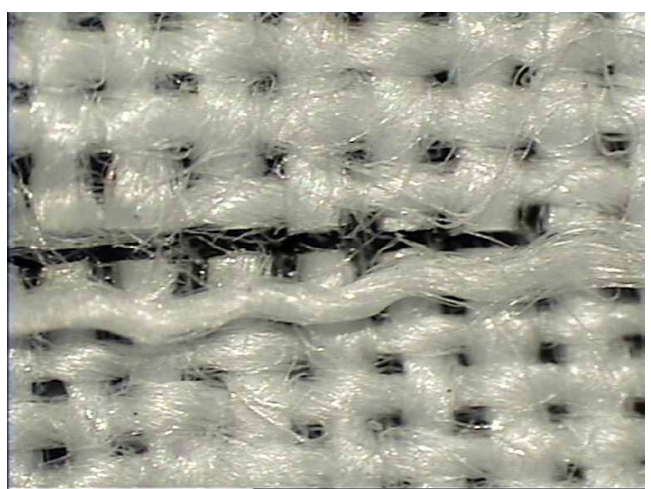

Figure 5: Fibre level, this would be categorised as 0 , due to the cut having no loose fibres.

a majority of loose fibres, then this would have been categorised as 3 (Figure 6).

In order to generate reproducible results, a pendulum-based 'slashing machine' was constructed at the University of Huddersfield. This consisted of a weighted arm with a clamp to hold the implement. A frame was fixed in place at the bottom of the arc, which held a piece of $100 \%$ cotton sheeting fabric (this frame had an adjustable height). The cotton was made from single weave (one under and over) and per $1 \mathrm{~cm}^{3}$ the material consisted of a weave density of 30 . The weighted arm was then lifted to a predetermined height and released. The arm would swing down and 'slash' through the fabric before being caught on the other side. The resulting damage would then be categorised as above. The variables explored were five different implements and increased force of slashing (adjusted by raising the height of the swinging arm prior to release, in order to raise the momentum).

\section{Length of damage}

Following each cut, the length of the slash cuts was measured between two edges of the cut that were the furthest apart. These measurements (in $\mathrm{mm}$ ) were used for the basis of all statistical analyses.

\section{Extent of fraying}

Another parameter explored in this study was the fraying of the damage. The term 'fraying' is used to refer to the extent of the displacement of the yarn out of the weave. If an implement is sufficiently sharp, it should cut through the fabric with minimal removal of the yarn out of the weave (Figure 1), whereas if the implement is sufficiently blunt, it should 'pull' some of the yarn out of the weave, rather than cut through it (Figure 4).

The fray was measured at yarn level and measured using Motic software using $\mathrm{x} 7$ magnification and recorded in $\mathrm{mm}$. The extent of fraying was recorded by measuring the distance from the edge of the cut yarns to the nearest intact warp/weft.

\section{Scalpel blunting}

The RSI was recorded on a new scalpel, which was then run gently over a whetstone to help the blade blunt quickly. The RSI was again recorded and the blade was then used to slash $100 \%$ cotton fabric. The blunting experiment was continued until the scalpel reached its bluntest point. This process was carried out in order to compare the differences between sharp and blunt blades, as ideally the blunter a blade; the shorter the damage length and more threads will be pulled from the yarn, leaving many loose fibres.

\section{Statistical analysis}

Paired sample T-tests were carried out, with the null-hypothesis being that the means of measurements from the slashed fabrics caused by implements of different blade sharpness were equal, thus indicating that varying sharpness of the implements had no effect on any features of the slashed fabric. The alternative hypothesis was that at least one of the means of the measurements from the slashed fabric was caused by implements of differing blade sharpness, thus indicating that varying

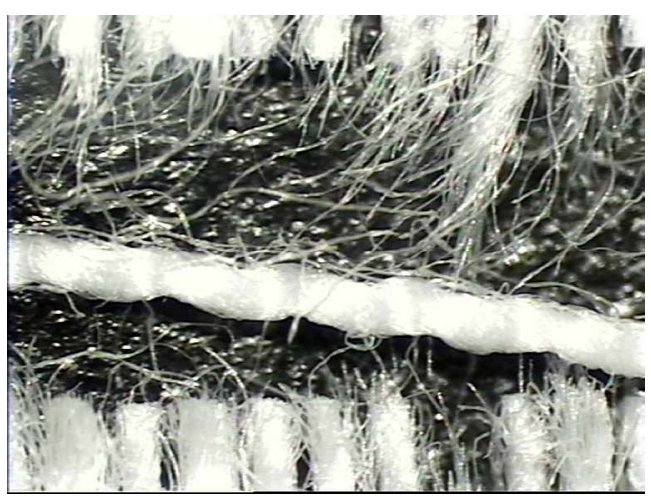

Figure 6: Fibre level, this would be categorised as 2, due to the cut having a majority of loose fibres. However if the bottom yarns also had a majority of loose fibres, then this would have been categorised as 3 . 
Citation: Bostock E, Burdon Parkes GM, Williams G (2013) A Novel Method for the Analysis of Slash Cuts to Clothing. J Forensic Res 4: 197. doi:10.4172/2157-7145.1000197

Page 4 of 7

the blade sharpness had an effect on the parameters of the slash cut. A paired sample T-test was carried out, as opposed to an ANOVA, due to the assumptions that the samples were independent and that the variances of the populations being equal were unreasonable.

\section{Results}

Knife descriptions and codes with statistics from the blade sharpness test were given in the Table 3 .

Table 4 shows the relative sharpness of all knives, using individual threads from the sharpest to the bluntest. It was observed that K14a had a similar RSI to the dowel, due to the maximum tensile strength of the thread being reached. The knives in bold were the implements used in this study.

Figure 7 shows the relative sharpness in knife order using 100\% cotton sewing thread.

Figure 8 shows the relative sharpness in knife order using 100\% cotton sheeting thread.

Figure 9 shows the relative sharpness in knife order using 100\% silk thread.

Figure 10 shows the relative sharpness in knife order using $100 \%$ polyester thread.

\begin{tabular}{|c|c|c|c|c|c|c|c|c|}
\hline Knife Description & Knife Code & $\begin{array}{l}\text { Cotton Sewing } \\
\text { Average }\end{array}$ & $\begin{array}{l}\text { Cotton Sheeting } \\
\text { Average }\end{array}$ & Silk Average & $\begin{array}{l}\text { Polyester } \\
\text { Average }\end{array}$ & Overall Mean & STD DEV & STD DEV\% \\
\hline Scalpel & Scalpel & 50 & 40 & 50 & 47 & 47 & 4.9 & 10 \\
\hline Bread knife & $\mathrm{K} 1$ & 467 & 478 & 506 & 611 & 515 & 66.1 & 13 \\
\hline Chef knife & $\mathrm{K} 2$ & 406 & 389 & 489 & 450 & 433 & 48.0 & 11 \\
\hline Carving knife & K3 & 478 & 506 & 489 & 600 & 518 & 61.6 & 12 \\
\hline Blunt Veg knife & K4 & 470 & 500 & 350 & 444 & 441 & 74.1 & 17 \\
\hline Utility knife & K5 & 500 & 428 & 578 & 572 & 519 & 67.9 & 13 \\
\hline Sharp Veg knife & K6 & 450 & 383 & 283 & 583 & 425 & 123.4 & 29 \\
\hline Large Boning knife & $\mathrm{K} 7$ & 721 & 661 & 1033 & 805 & 805 & 234.9 & 30 \\
\hline Large Carving knife & K8 & 528 & 472 & 522 & 684 & 552 & 84.6 & 15 \\
\hline Large Chef's knife & K9 & 539 & 539 & 606 & 672 & 589 & 70.2 & 12 \\
\hline \multicolumn{9}{|l|}{ Double Bladed knife } \\
\hline 0 Side & K10a & 772 & 694 & 939 & 1217 & 906 & 207.4 & 23 \\
\hline 1 Side & $\mathrm{K} 10 \mathrm{~b}$ & 700 & 678 & 761 & 905 & 761 & 90.6 & 12 \\
\hline Fillet knife & K11 & 572 & 550 & 645 & 795 & 640 & 98.9 & 15 \\
\hline Stanley knife & $\mathrm{K} 12$ & 100 & 106 & 106 & 144 & 114 & 18.1 & 16 \\
\hline Medium bladed flick knife & K13 & 483 & 450 & 589 & 739 & 565 & 12.6 & 20 \\
\hline \multicolumn{9}{|l|}{ Double bladed diving knife } \\
\hline Straight side & K14a & 1061 & 750 & 1183 & 1455 & 1112 & 260.8 & 24 \\
\hline Curved side & $\mathrm{K} 14 \mathrm{~b}$ & 500 & 522 & 678 & 672 & 593 & 95.4 & 16 \\
\hline Small bladed flick knife & K15 & 622 & 539 & 722 & 950 & 708 & 153.9 & 22 \\
\hline Kitchen devil utility knife & SK1 & 283 & 350 & 417 & 350 & 350 & 67.6 & 19 \\
\hline Dowel & Dowel & 1450 & 733 & 1233 & 1833 & 1313 & 409.2 & 22 \\
\hline
\end{tabular}

Table 3: Knife descriptions and codes with statistics from the blade sharpness test.

\begin{tabular}{|c|c|c|c|c|c|c|c|}
\hline Cotton Sewing Thread & RSI & Cotton Sheeting Thread & RSI & Silk Thread & RSI & Polyester Thread & RSI \\
\hline Scalpel & 0.05 & Scalpel & 0.05 & Scalpel & 0.04 & Scalpel & 0.03 \\
\hline K12 & 0.07 & K12 & 0.14 & K12 & 0.09 & $\mathrm{~K} 12$ & 0.08 \\
\hline SK1 & 0.27 & SK1 & 0.48 & K6 & 0.24 & SK1 & 0.24 \\
\hline $\mathrm{K} 2$ & 0.28 & K6 & 0.52 & K4 & 0.28 & K4 & 0.24 \\
\hline K6 & 0.31 & $\mathrm{~K} 2$ & 0.53 & SK1 & 0.34 & $\mathrm{~K} 2$ & 0.25 \\
\hline $\mathrm{K} 1$ & 0.32 & K5 & 0.58 & $\mathrm{~K} 2$ & 0.40 & K7 & 0.28 \\
\hline $\mathrm{K} 4$ & 0.32 & K13 & 0.61 & K3 & 0.40 & K5 & 0.31 \\
\hline K3 & 0.3 & K8 & 0.64 & $\mathrm{~K} 1$ & 0.41 & K6 & 0.32 \\
\hline K13 & 0.33 & $\mathrm{~K} 1$ & 0.65 & K8 & 0.42 & K3 & 0.33 \\
\hline K5 & 0.34 & K4 & 0.68 & K5 & 0.47 & $\mathrm{~K} 1$ & 0.33 \\
\hline $\mathrm{K} 14 \mathrm{~b}$ & 0.34 & K3 & 0.68 & K13 & 0.48 & K9 & 0.37 \\
\hline $\mathrm{K} 8$ & 0.36 & $\mathrm{~K} 14 \mathrm{~b}$ & 0.71 & K9 & 0.49 & $\mathrm{~K} 14 \mathrm{~b}$ & 0.37 \\
\hline K9 & 0.37 & K9 & 0.73 & K11 & 0.52 & K8 & 0.37 \\
\hline K11 & 0.39 & K15 & 0.73 & $\mathrm{~K} 14 \mathrm{~b}$ & 0.55 & $\mathrm{~K} 13$ & 0.40 \\
\hline K15 & 0.43 & K11 & 0.74 & K15 & 0.59 & K11 & 0.43 \\
\hline $\mathrm{K} 10 \mathrm{~b}$ & 0.48 & K7 & 0.89 & $\mathrm{~K} 10 \mathrm{~b}$ & 0.62 & $\mathrm{~K} 10 \mathrm{~b}$ & 0.49 \\
\hline K7 & 0.50 & $\mathrm{~K} 10 \mathrm{~b}$ & 0.92 & K10a & 0.76 & K15 & 0.52 \\
\hline K10a & 0.53 & K10a & 0.94 & K7 & 0.84 & K10a & 0.66 \\
\hline $\mathrm{K} 14 \mathrm{a}$ & 0.73 & Dowel & 0.99 & $\mathrm{~K} 14 \mathrm{a}$ & 0.96 & $\mathrm{~K} 14 \mathrm{a}$ & 0.79 \\
\hline Dowel & 1.00 & $\mathrm{~K} 14 \mathrm{a}$ & 1.00 & Dowel & 1.00 & Dowel & 1.00 \\
\hline
\end{tabular}

Table 4: Relative sharpness of all knives, using individual threads from the sharpest to the bluntest. 
Citation: Bostock E, Burdon Parkes GM, Williams G (2013) A Novel Method for the Analysis of Slash Cuts to Clothing. J Forensic Res 4: 197. doi:10.4172/2157-7145.1000197

Page 5 of 7



Figure 7: Relative sharpness in knife order using $100 \%$ cotton sewing thread.

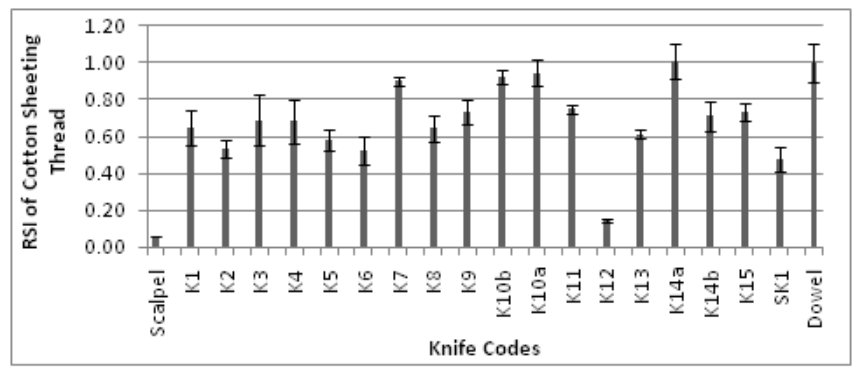

Figure 8: Relative sharpness in knife order using 100\% cotton sheeting thread.

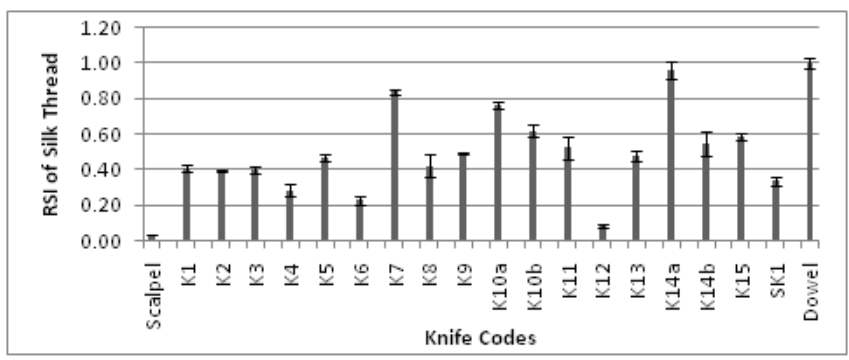

Figure 9: Relative sharpness in knife order using $100 \%$ silk thread.

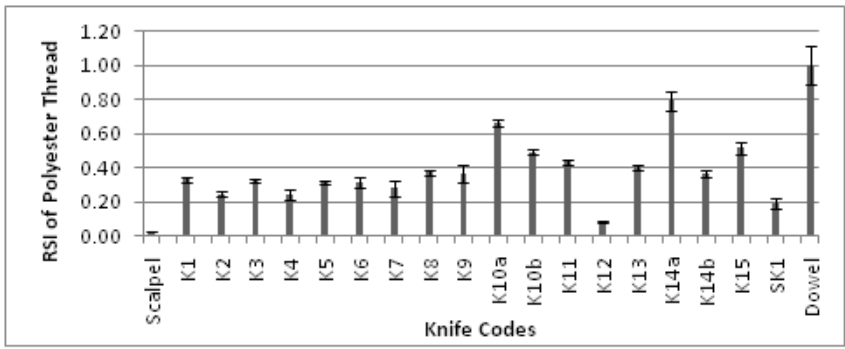

Figure 10: Relative sharpness in knife order using 100\% polyester thread.

Figure 11 shows the categorisation of a slash cut caused by four different implements.

Paired sample T-tests were carried out on the overall data $(n=8)$ and the values were significantly different $(p=>0.05)$ between the scalpel and each of the knives. However, there was no significant difference between the sharp (K6) and the blunt (K4) knives ( $\mathrm{p}=0.875$ ); the sharp and the utility knives $(\mathrm{p}=0.785)$ and between the utility and the blunt knives $(\mathrm{p}=1)$.The numbers on the $\mathrm{x}$-axis represent the angle away from a loose hang from which the knife was released, in other words, it corresponds to the height of the knife as it was released. This result shows no significant differences between changing the angle of release.

Figure 12 shows the correlation between the relative sharpness index and the categorisation damage caused by being slashed by the specific implement (steak knife, scalpel, (SK1) utility knife, (K6) sharp knife, and the (K4) blunt knife). Refer to Table 4 for the order of implements.

$\mathrm{R}^{2}$ values: cotton sheeting $=0.88$, silk $=0.89$, cotton sewing 0.81 , and polyester $=0.80$.

Figure 13 shows the correlation between the relative sharpness index and the extent of the fraying damage caused by being slashed by the specific implement (steak knife, scalpel, (SK1) utility knife, (K6) sharp knife, and the (K4) blunt knife). Refer to Table 4 for the order of implements.

$R^{2}$ value: cotton sewing $=0.71$, cotton sheeting $=0.36$, silk $=0.65$ and polyester $=0.46$.

Figure 14 shows the correlation between the categorisation level and the extent of the fraying damage caused by being slashed by the

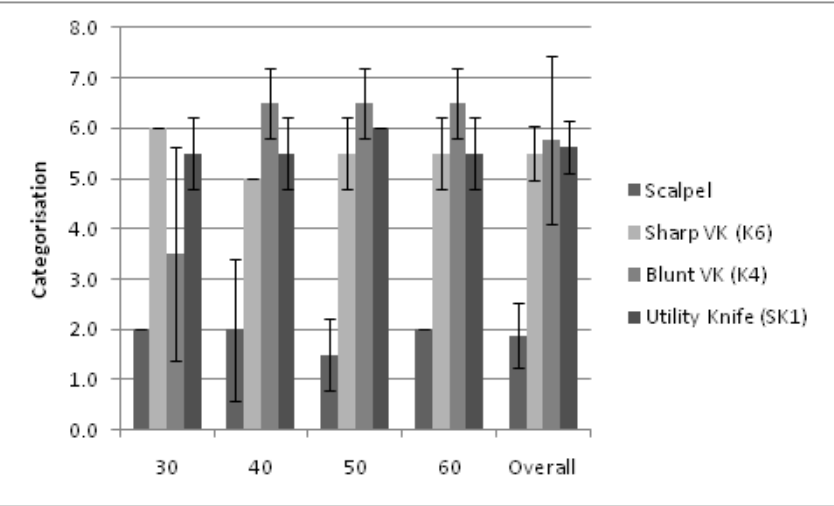

Figure 11: The categorisation of a slash cut caused by four different implements.

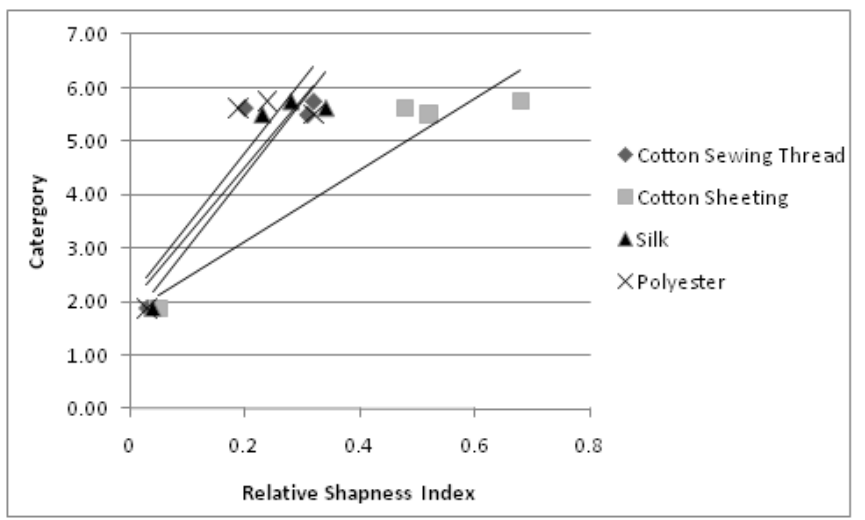

Figure 12: The correlation between the relative sharpness index and the categorisation damage caused by being slashed by the specific implement (steak knife, scalpel, (SK1) utility knife, (K6) sharp knife, and the (K4) blunt knife). 


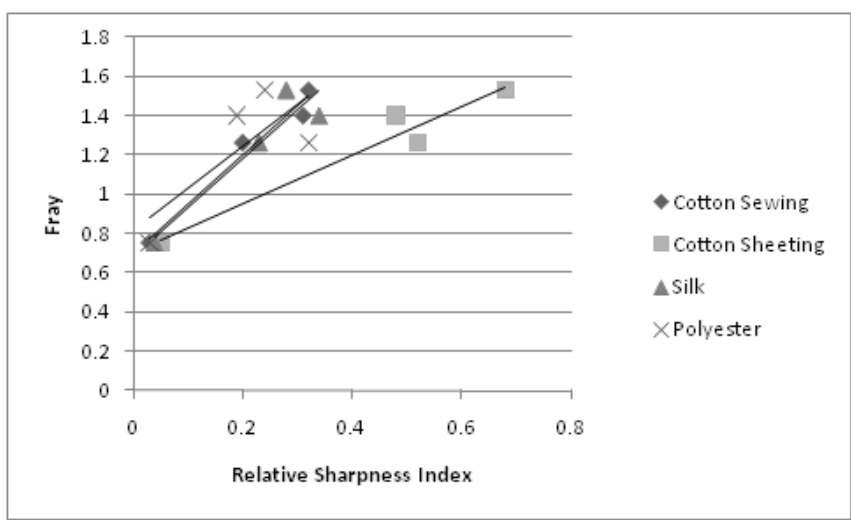

$R^{2}$ value: cotton sewing $=0.71$, cotton sheeting $=0.36$, silk $=0.65$ and polyester $=0.46$

Figure 13: The correlation between the relative sharpness index and the extent of the fraying damage caused by being slashed by the specific implement (steak knife, scalpel, (SK1) utility knife, (K6) sharp knife, and the (K4) blunt knife).

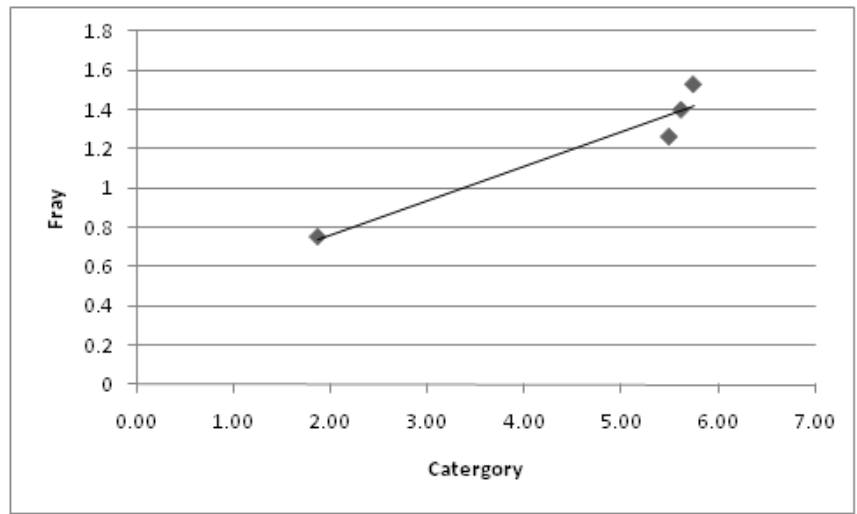

The graph indicated an $\mathrm{R}^{2}$ value of 0.56

Figure 14: The correlation between the categorisation level and the extent of the fraying damage caused by being slashed by the specific implement (steak knife, scalpel, (K6) sharp knife, (SK1) utility knife and the (K4) blunt knife).

specific implement (steak knife, scalpel, (K6) sharp knife, (SK1) utility knife and the (K4) blunt knife).

The graph indicated an $\mathrm{R}^{2}$ value of 0.56 .

However if the scalpel and steak knife were removed from the experiment, then the $\mathrm{R}^{2}$ value increases to 0.99 .

Figure 15 shows the correlation between the relative sharpness index of the blunting scalpel experiment and the length of damage caused by being continually slashed by the specific implement. This gives an $\mathrm{R}^{2}$ value of 0.93 .

\section{Discussion}

The aim of this study was to determine whether there is a correlation between a slash cut and the implement that caused the slash damage. The feature of the implement that was being investigated in this study was the sharpness of the blade. Preliminary work and case work experience demonstrated that the sharpness of the implement had a direct effect on the appearance of the slash cut, which is commonsense; but was it possible to use the information from the slash cut to form a reliable opinion concerning the sharpness of the implement?

The knives used in all these experiments consisted of a steak knife, a 10 blade scalpel, a utility knife (SK1), a sharp vegetable knife (K6) and a blunt vegetable knife (K4).

\section{Blade sharpness testing}

All available knives were given a sharpness test and it was noted that different forces were required for individual threads to break, due to the uniformity of the manufacturing process. Due to this factor, all of the results relating to threads have been individually calculated (Figures 7-10).

When using the dowel to measure ultimate bluntness, the threads broke due to the maximum tensile strength of the threads being reached. This was also the case for K14a, when cotton sheeting thread was used i.e. the blade was very blunt and was unable to cut the thread before it snapped. This may also apply to cases where implements had a high RSI value of 0.9 and above.

When comparing the sharpness test with a subjective assessment of the sharpness, it is clear that this method is accurate and effective.

\section{Categorising clothing damage}

When combining the results of categorisation alongside the results of the relative sharpness index, it was shown that cotton sheeting had the highest $\mathrm{R}^{2}$ value (0.92) and the polyester had the lowest $\mathrm{R}^{2}$ value (0.78).

These results show that the lower the categorisation measurement, the sharper the knife was. This also showed that there was a correlation when combining categorisation and the relative sharpness index measurements, therefore demonstrating that categorisation can be linked to sharpness.

\section{Length of damage}

The principle behind this experiment was to show that the sharper the blade was, the less force was required to cut the fabric. The experiment showed that the sharp scalpel blade was able to glide through the material whilst cutting, therefore creating a longer



However if the scalpel and steak knife were removed from the experiment, then the $\mathrm{R}^{2}$ value increases to 0.99

Figure 15: The correlation between the relative sharpness index of the blunting scalpel experiment and the length of damage caused by being continually slashed by the specific implement. This gives an $R^{2}$ value of 0.93 . 
smoother damage path than the blunt vegetable knife, as this struggled to cut the material, inevitably creating a shorter uneven damage path. This experiment was carried out in an attempt to identify the RSI value at which the blade may fail to cut entirely through the fabric. Such a value was not identified

It was found that there was a poor correlation between length of damage and the RSI, categorisation and fray damage. Therefore, it can be seen that the length of the damage did not assist in providing information regarding the nature of the slashing implement.

\section{Extent of fraying}

A correlation between the fray results and the RSI could be observed to a lesser or greater extent depending on the fabric type.

The highest $\mathrm{R}^{2}$ value was 0.97 and came from the cotton sewing thread; however the cotton sheeting thread closely followed with an $\mathrm{R}^{2}$ of 0.95 . The lowest value came from polyester thread $(0.78)$. This element was also considered within the damage categorisation and when the categorisation was compared alongside the fray damage, the $\mathrm{R}^{2}$ value was 0.93 , indicating that the less fray damage was present, the lower the categorisation measurement and therefore there was a correlation when using both fray and categorisation measurements.

However, when data relating to the scalpel was removed from this experiment, a higher correlation could be observed $\left(\mathrm{R}^{2}=0.99\right)$.

\section{Scalpel bluntness}

The scalpel was able to cut the fabric with no difficulties until it reached 0.23 RSI (Figure 15). At 0.23 RSI it was observed that the cuts were smaller than previous cuts made and there was also pushing of the material (the yarn was moved out of the plane of the fabric). The damage length consists of both the length of the cutting and scoring i.e. it started with a cut and ended in scoring.

At 0.32 RSI (the bluntest measurement), the scalpel blade was no longer able to cut the fabric and could only push the material out of the way. The damage length that has been recorded was the scoring that the blade left behind.

When combining the blunting experiment with the RSI results, a correlation is seen and the $\mathrm{R}^{2}$ value is 0.93 .

It was no surprise that the sharper the implement, the smoother the damage. This study demonstrates, using a simple variable, the proof of principle that it is possible to correlate a quantifiable feature of a cut with a quantifiable feature of the implement. Considerable further work is required to translate this proof of principle into a valid operational forensic tool.
Further studies will expand this to include a wider range of implements (Table 3 ) upon the same materials, as well as other materials commonly used in garment manufacture. The data will be used to create a database which can be used to relate damage categorisation to blade sharpness or even to a particular type of implement.

In time, this data will also be applied to a number of case work samples, both mock cases and real cases, in conjunction with our own in-house forensic practitioners.

\section{Conclusions}

Two new techniques have been identified, which allow for a quantifiable assessment of damage to fabric and of blade sharpness. A correlation between these two parameters has been demonstrated statistically, which supports empirical observations. This also demonstrates the principle that observations of damage can provide information relating to the relative sharpness of an implement and therefore allow for the presentation of far more reliable and robust forensic evidence.

\section{References}

1. Ciallella C, Caringi C, Aromatario M (2002) Wounds inflicted by survival-knives. Forensic Sci Int 126: 82-87.

2. Nic Daéid N, Cassidy M, McHugh S (2008) An investigation into the correlation of knife damage in clothing and the lengths of skin wounds. Forensic Sci Int 179: 107-110.

3. Sitiene R, Varnaite J, Zakaras A (2004) Complex investigation of body and clothing injuries during the identification of the assault instrument. Forensic Sci Int 146 Suppl: S59-60.

4. Bleetman A, Hughes $H$, Gupta $V(2003)$ Assailant technique in knife slash attacks. J Clin Forensic Med 10: 1-3.

5. Bleetman A, Watson CH, Horsfall I, Champion SM (2003) Wounding patterns and human performance in knife attacks: optimising the protection provided by knife-resistant body armour. J Clin Forensic Med 10: 243-248.

6. Causin V, Marega C, Schiavone S (2005) Cuts and tears on a paper towel: a case report on an unusual examination of damage. Forensic Sci Int 148: 157-162.

7. Monahan DL, Harding HWJ (1990) Damage to Clothing-Cuts and Tears. Journal of Forensic Science 35: 901-12.

8. Horsfall I, Watson C, Champion S, Prosser P, Ringrose T (2005) The effect of knife handle shape on stabbing performance. Appl Ergon 36: 505-511.

9. Taupin JM (1998) Testing conflicting scenarios--a role for simulation experiments in damage analysis of clothing. J Forensic Sci 43: 891-896.

10. Allard JE (1997) The collection of data from findings in cases of sexual assault and the significance of spermatozoa on vaginal, anal and oral swabs. Sci Justice 37: 99-108.

11. Johnson N, Physical damage to textiles. Department of Textile Technology, School of Fibre Science and Technology, University of New South Wales. 